\title{
La educación de la mirada: el mito de la Gigantomaquia en el arte como herramienta propagandística a lo largo de la historia
}

Elena Bellido-Pérez*

\section{Resumen}

En este texto se realiza un recorrido histórico por algunas de las obras más relevantes de la historia del arte en las que se ha representado el mito de la Gigantomaquia, procurando dibujar un panorama representativo desde los inicios clásicos hasta la contemporaneidad. El objetivo es determinar los valores atemporales que ha contenido siempre esta iconografía y que han servido de herramienta para la legitimación del poder de distintas formas gubernamentales. Con ello, se incide en la eficacia comunicativa de las representaciones artísticas de este mito, las cuales se dirigían a un espectador cuya mirada ya estaba educada en una interpretación concreta desde la etapa clásica.

Palabras clave: arte, propaganda, mitología, poder, educación

The education of the gaze: the Gigantomachy myth in art as propaganda tool along History

\section{Abstract}

In this text, a historical journey is made through some of the most relevant works in the art history in which the myth of the Gigantomachy has been depicted, trying to draw a representative panorama from the classical beginnings to the present day. The objective is to determine the timeless values that this iconography has always contained and that have served as a tool

Universidad de Sevilla: Sevilla, Andalucía, ES. 
for the legitimization of power in different governmental forms. Thus, the communicative effectiveness of the artistic representations of this myth is highlighted; representations that addressed a spectator whose gaze was already educated in a concrete interpretation from the classical stage.

Keywords: art, propaganda, mythology, power, education

\section{Introducción}

La mitología clásica no solamente ha funcionado como base educativa a la hora de explicar la realidad circundante en las antiguas civilizaciones, sino que su continua explotación en esculturas o pinturas ha dado lugar a la consolidación de una serie de valores atemporales. Entre dichos valores, la victoria o la superioridad física o moral que estos personajes (y los episodios que protagonizaban) llevaban arraigada en el arte ha servido a lo largo de la historia para realizar un paralelismo entre las elogiables cualidades de los dioses, diosas y héroes de antaño y las de las personas que ostentan el poder en cada época.

Concretamente, los mitos clásicos sobre la lucha por el poder en el Olimpo constituyen un tema que, de entrada, sugiere una profunda explotación iconográfica. En particular, se pueden identificar dos mitos que versan sobre este tipo de enfrentamiento: la Titanomaquia y la Gigantomaquia. Dada la polarización tan acusada que existe entre Titanes y dioses o Gigantes y dioses, ambos mitos se prestan a una representación artística con evidentes funciones de propaganda. El motivo es claro: la población podía identificar con facilidad, a través de estos episodios, quiénes eran los vencedores y quiénes los vencidos; quiénes eran los que habían traído la gloria al reino (asociándolos a los dioses del Olimpo) y quiénes eran los enemigos que pretendían arrebatarles el poder (asociándolos a los Gigantes o Titanes que acabaron derrotados en el subsuelo). Dependiendo de la entidad que encargase la obra, la lectura propagandística del episodio quedaba patente.

Este texto trata sobre la educación de la mirada del espectador en cuanto a una sola temática iconográfica, cuyo significado de base ha permanecido invariable a lo largo de la historia, mostrando 
así el profundo arraigo del significado de ciertas imágenes en el imaginario colectivo. Se desarrolla así el mito de la Gigantomaquia en el arte, dado que, como indica Miguel Ángel Elvira Barba, la Titanomaquia narra el enfrentamiento que Zeus tuvo con su padre para destronarlo, lo que hacía de su significado un asunto "difícil de defender en clave política o moral" (2008: 60). Por lo tanto, la Gigantomaquia acabó siendo más representada en el arte, hasta el punto de que aunque los títulos de algunas obras remitan a la lucha entre dioses y Titanes, "casi siempre", afirma Elvira Barba, "se trata de un error, y [...] el titulo correcto es Lucha de los dioses contra los Gigantes" (2008: 60). Para clarificar esta posible confusión en el arte entre dos episodios diferentes y separados temporalmente, se reseñan a continuación ambos mitos.

\section{La Gigantomaquia en las fuentes clásicas}

Aunque hubo representaciones artísticas anteriores (Elvira Barba, 2008: 91), la primera alusión literaria al enfrentamiento entre dioses y Gigantes se debe a Píndaro (1984: 191). En su Teogonía, Hesíodo únicamente narra la Titanomaquia (1978: 98-107), y solo menciona a los Gigantes (1978: 79) para referirse a los hijos de Gea que nacieron de las gotas de sangre de los genitales mutilados de Urano:

Pues cuantas gotas de sangre salpicaron, todas las recogió Gea. Y al completarse un año, dio a luz a las poderosas Erinias, a los altos Gigantes de resplandecientes armas, que sostienen en su mano largas lanzas, y a las Ninfas que llaman Melias sobre la tierra ilimitada.

No obstante, estos Gigantes no protagonizaron ningún episodio en la Teogonía, sino que la narración más extensa de la Gigantomaquia la ofrece Apolodoro (1985: 52-54), quien los describe en su Biblioteca Mitológica de la siguiente manera: "insuperables por su tamaño e invencibles por su fuerza, mostraban temible aspecto, con espesa pelambre pendiente de la cabeza y el mentón, y escamas de dragón como pies" (1985: 52). De todos ellos, los 
más sobresalientes eran Porfirio y Alcioneo. Según Apolodoro, los Gigantes combatían contra el Olimpo arrojando al cielo encimas encendidas y piedras, y sobre ellos se había vaticinado que serían invencibles por los dioses a menos que un mortal luchase del lado del Olimpo. Conociendo esta profecía y adelantándose a la misma, Gea hizo crecer una planta que transformase a sus hijos en seres completamente inmortales; pero Zeus, tras ordenar que ni Eros, ni Selene ni Helios hicieran su aparición para que no fomentasen el desarrollo de la sustancia, logró destruir dicha planta. Con la ayuda de Atenea, Zeus trajo al mortal Heracles para que participase en esta lucha contra los Gigantes. A partir de ahí, Apolodoro narra con detalle la caída de los Gigantes a manos de los dioses: Apolo, Dioniso, Hécate, Hefesto, Atenea, Posidón, Hermes, Artemisa y las Moiras son las divinidades que combatieron en la Gigantomaquia, reservando los últimos golpes mortales a manos de Zeus y Heracles.

Por su parte, la Titanomaquia consistió en una lucha entre Titanes y dioses del Olimpo que duró más de diez años. Los Titanes son, al igual que los Gigantes, hijos de Urano y Gea. Según Hesíodo (1978: 78) y Apolodoro (1985: 40), Gea convenció a los Titanes para que atacasen a su padre y salvasen a sus hermanos (los primeros hijos de Gea y Urano), encerrados en el Tártaro, un recóndito y oscuro lugar del subsuelo. Para ello, le entregó una hoz a su hijo, el titán Cronos, quien mutiló los genitales de su padre Urano. Apolodoro (1985: 40-42) cuenta cómo, destronado Urano, Cronos se hace con el poder, desposa a su hermana, la titánide Rea, y se traga a todos los hijos que engendra con ella (los dioses del Olimpo), ya que se había vaticinado que uno de ellos le arrebataría el poder. No obstante, Rea logra salvar a Zeus, quien, ya adulto, le pide ayuda a Metis para hacer que su padre vomitase al resto de sus hermanos. Una vez todos en pie, entablan una lucha de diez años contra los Titanes por el poder en el Olimpo, que finalmente se resuelve con los Titanes encerrados en el Tártaro. La Gigantomaquia, por consiguiente, es un episodio posterior a la Titanomaquia, en el que Gea 
utiliza a sus hijos los Gigantes para vengarse de aquellos dioses que habían encerrado a sus otros hijos los Titanes ${ }^{1}$.

Según Elvira Barba (2008: 91), a finales del siglo IV a. C. se discutió sobre el lugar donde ocurre la Gigantomaquia, cobrando fuerza la teoría de su desarrollo en el sur de Italia, lo cual quedará reflejado iconográficamente en la asociación que se establece entre los Gigantes y los volcanes de esta región. Posteriormente, Ovidio también incluirá este episodio en sus Metamorfosis redundando en esta idea: los Gigantes intentan llegar al Olimpo construyendo montañas y acaban fulminados por Zeus y enterrados bajo ellas ${ }^{2}$. Con una breve alusión, la iconografía sobre la Gigantomaquia que se realizará a partir del Renacimiento tiene a Ovidio como referencia (2008: 92).

\section{La Gigantomaquia en la Historia del Arte: desde el siglo VI a.C. hasta el siglo XX}

Una de las primeras representaciones de la Gigantomaquia, que Elvira Barba comenta como "el paso decisivo hacia la difusión del tema” (2008: 91), es el lado norte del friso del Tesoro de los Sifnios, en Delfos (imagen 1). En el fragmento que aparece en la imagen se observa que los Gigantes están representados como hoplitas; aún faltaban más de trescientos años para que se diera a conocer la descripción física que Apolodoro realiza de ellos. A pesar de los fragmentos que se han desprendido de la piedra, se aprecia un león tirando de un carro en el que se alza una figura femenina. Se trata de Cibeles (Delgado Linacero, 1999: 117), la gran diosa frigia que aquí es asociada directamente con Rea, madre de las

\footnotetext{
1 En la compilación de mitos griegos realizada por Robert Graves, queda patente este orden cronológico: primero sucede la Titanomaquia (2009: 48-50) y después la Gigantomaquia (2009: 147-150).

2 'Y para que no estuviera que las tierras más seguro el arduo éter, que aspiraron dicen al reino celeste los Gigantes, y que acumulados levantaron hacia las altas estrellas sus montes. Entonces el padre omnipotente enviándoles un rayo resquebrajó el Olimpo y sacudió el Pelión del Osa, a él sometido; sepultados por la mole suya, al quedar sus cuerpos siniestros yacentes, regada de la mucha sangre de sus hijos dicen que la Tierra se impregnó” (Ovidio, 1983: 20).
} 
divinidades olímpicas que está ayudando a sus hijos en este arduo enfrentamiento.

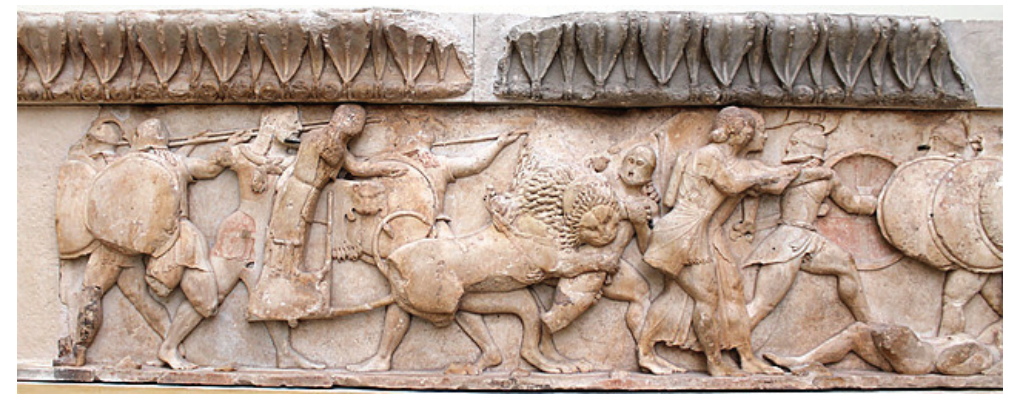

Imagen 1: Friso norte del Tesoro de los Sifnios (Delfos). Autor desconocido (530 a.C.). Museo Arqueológico de Delfos

Dado que Sifnos era una isla del Egeo que trataba de incorporarse a la vida cultural y comercial griega que dirigía Atenas, la representación de la batalla suponía un elogio a la supremacía ateniense asimilada con las divinidades del Olimpo vencedoras (Delgado Linacero, 1999: 117). Algunos años más tarde, tal y como afirma Watrous (1982: 162), esta misma lectura propagandística de la Gigantomaquia se acentuará al integrarse en las metopas del lado este del Partenón de Atenas y, además, en el interior del escudo que portaba la Atenea Partenos. Se trata, por consiguiente, de una declaración rotunda de la supremacía del orden político ateniense.

En este periodo arcaico también se encuentran varias representaciones de la Gigantomaquia en cerámica. Una de las mejores conservadas es un ánfora ática cuyas figuras se atribuyen al pintor de Lisipedes (imagen 2). En ella, Zeus (con un rayo en su mano derecha) y Heracles (ataviado con la piel del león de Nemea), están luchando en una cuadriga tirada por dos caballos ${ }^{3}$, y a su lado Atenea ataca a un gigante. En la imagen se observa a la diosa con sus atributos característicos hiriendo al que podría ser Encélado. Aunque el enfrentamiento entre Atenea y Encélado es descrito por

\footnotetext{
3 https://www.britishmuseum.org/collection/object/G_1839-1109-3 (2-32021). 
Apolodoro (1985: 53), ya aparece en representaciones anteriores como esta, por lo que es posible que se describiese en otras fuentes hoy desconocidas. Según Rodríguez López, la frecuencia de esta escena se debe a la voluntad de representar "la supremacía de Atenas y de su diosa tutelar sobre otras poleis” (2009: 12). Además, señala la autora, dado que este tipo de productos pertenecían a la elite de la sociedad, servían como catalizador de las ideas predominantes a la hora de trasladarlas al ámbito doméstico (2009: 12).

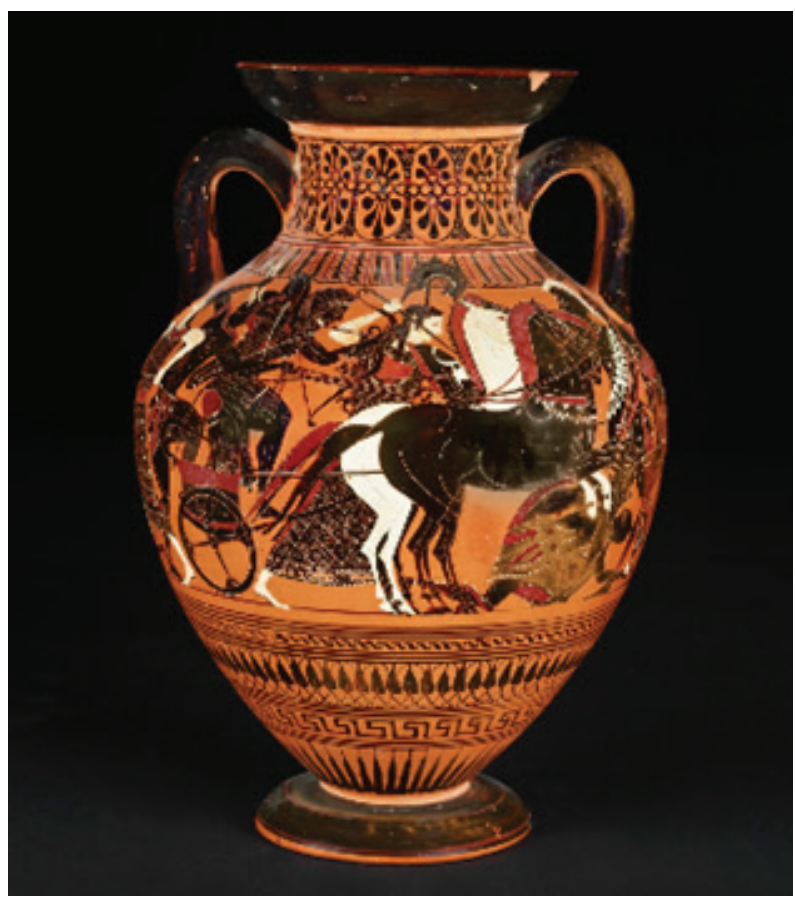

Imagen 2: Ánfora ática de figuras negras. Atr. Lisipedes (520-500 a.C.). Museo Británico (Londres)

Sin lugar a dudas, una de las más espléndidas representaciones de esta batalla es la que decora todo el friso exterior del Altar de Pérgamo, ya en el periodo helenístico (imagen 3). El despliegue técnico y las funciones propagandísticas del altar se unen en esta obra para desarrollar una Gigantomaquia de extraordinarias dimen- 
siones repleta de detalles. Eumenes II ordenó construir este altar para conmemorar su victoria sobre los gálatas de Tracia (Rodríguez López, 2009: 16), por lo que su lectura propagandística es evidente 4 , más aún cuando de la obra se extrae la intención del rey de realizar un paralelismo con la magnitud del Partenón de Atenas ordenado por Pericles. Así, a diferencia de la Gigantomaquia en la Grecia clásica, esta vez la obra se realiza "bajo el prisma ideológico y político de la monarquía atálida, continuadora de las ideas universalistas de Alejandro Magno y promotora de los modelos de la vida y las artes de la Atenas clásica” (Delgado Linacero, 1999: 122).

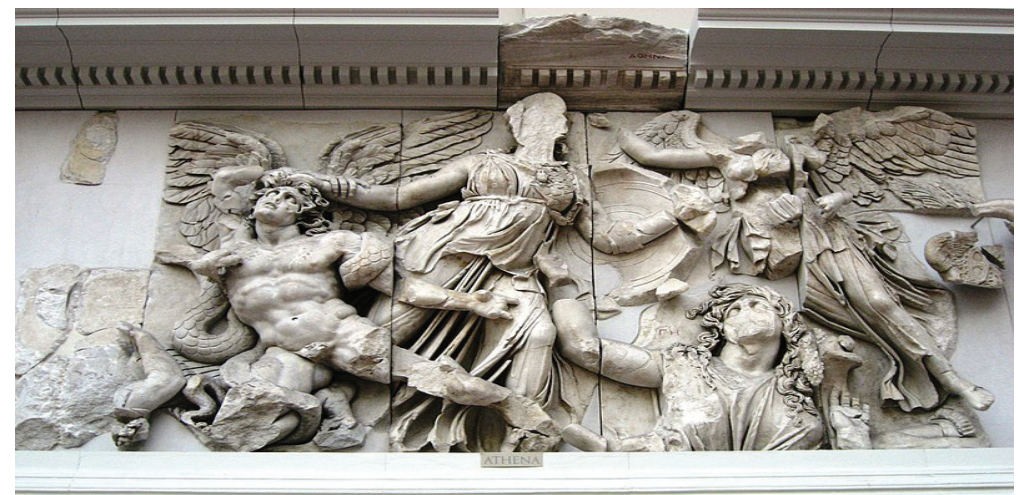

Imagen 3: Atenea y Niké luchando contra Alcioneo en el friso este del Altar de Pérgamo. VV.AA. (188 a.C). Museo de Pérgamo (Berlín)

$\mathrm{Al}$ igual que en el caso anterior, en la imagen 3 aparece Atenea, aunque esta vez atacando al gigante Alcioneo. Aunque Apolodoro no narra el enfrentamiento directo entre Atenea y Alcioneo, quien fue finalmente abatido por Heracles, sí deja constancia de la participación de la diosa en el ataque al gigante: "Éste [Heracles] primero disparó su arco contra Alcioneo, quien al caer en tierra se reanimó. Por consejo de Atenea, Heracles lo arrastró fuera de Palene y de este modo acabó con él” (1985: 53). Los Gigantes se

$4 \quad$ En este sentido, estudios como el de Whitaker (2005) han analizado ideológicamente esta obra. 
representan aquí asociados a las escamas de dragón en los pies a las que se refería Apolodoro (1985: 52); concretamente, algunas figuras ven transformadas sus piernas en serpientes, y otras, como el gigante de la imagen (cuya postura guarda un extraordinario parecido con la figura del Laocoonte y sus hijos), aparecen enredadas en serpientes. En la escena del fragmento del friso que aparece en la imagen, también se muestra la diosa de la Victoria ayudando a Atenea y, bajo ella, emerge Gea de la tierra, dispuesta a detener a Atenea en su lucha contra sus hijos los Gigantes. Según Elvira Barga, se trata de la mejor imagen de Gea en el arte, mostrándose “colosal e implorante" (2008: 47).

Más adelante en el tiempo, ya avanzado el Imperio Romano, encontramos una extraordinaria representación musivaria de los Gigantes siendo atacados por los dioses del Olimpo (imagen 4). Se trata de un mosaico que se encuentra en el triclinio de la Villa romana del Casale, en la localidad de Piazza Armerina (Sicilia). Forma parte de la decoración de un conjunto arquitectónico de cuarenta y cinco habitaciones, ocupando en total tres mil quinientos metros cuadrados (Wilson, 2012). No se ha logrado identificar a la persona propietaria que habitaba la villa, aunque Wilson sugiere algunos gobernadores de Sicilia como Domitius Latronianus o Betitius Perpetuus, u otros senadores romanos como L. Aradius Valerius Proculus o Ceionius Rufius Albinus (Wilson, 2012). En cualquier caso, la majestuosidad del complejo arquitectónico da a entender el origen aristocrático de la edificación.

Los Gigantes aparecen aquí (imagen 4) retorcidos de dolor, intentando zafarse de las flechas que Heracles les ha lanzado. Su caracterización como Gigantes es inequívoca dada la representación de la parte inferior de su cuerpo, convertida en serpientes siguiendo la descripción de Apolodoro. La estancia que decoraban era un comedor que se destinaba al descanso, donde podían entrar invitados de cualquier índole y sentirse intimidados por el mosaico, asociando los Gigantes con los enemigos del Imperio Romano. De todos modos, como indica Rodríguez López, "no es posible valorar el simbolismo de las figuras, aunque todo parece indicar que su inclusión pudiera obedecer a un programa iconográfico premeditadamente concebido" (2009: 19). 


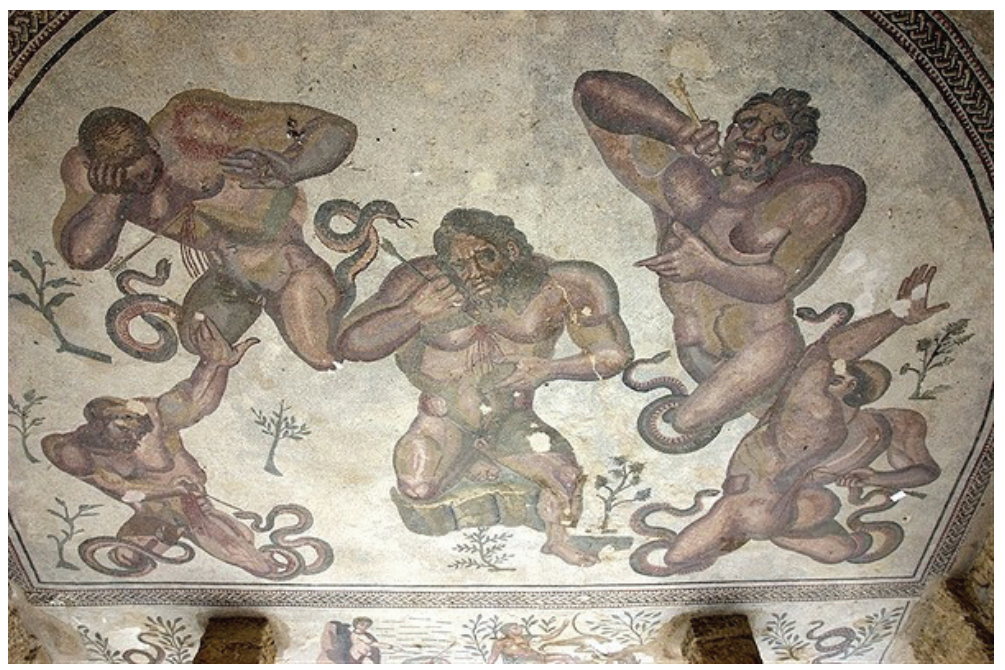

Imagen 4: Mosaico de los Gigantes en el triclinio de la Villa del Casale. Autor desconocido (siglos III-IV). Villa romana del Casale (Piazza Armerina, Sicilia)

La Gigantomaquia parece desaparecer durante el arte de la Edad Media, recuperándose posteriormente en el Renacimiento a través de la referencia de Ovidio (Elvira Barba, 2008: 92). De la etapa manierista del Renacimiento destacan de manera sobresaliente los frescos que relatan La caída de los Gigantes, los cuales ocupan toda una espléndida estancia (la Sala de los Gigantes) dentro del Palacio del Té, en Mantua (imagen 5). Giulio Romano fue el pintor encargado la representación de la escena. La batalla por el poder en el Olimpo se desarrolla con un movimiento ascensional que va desplazando la mirada del espectador hacia el trampantojo de la cúpula, haciéndole sentir atrapado por el carácter envolvente de la contienda. El todopoderoso Zeus, como describe Ovidio (1983: 20), es el artífice de la batalla, fulminando con su rayo a los Gigantes mientras el resto del Olimpo observa. Así, el plano terrenal y el celestial están perfectamente identificados a través de un espacio del que el espectador es partícipe: sobre él también está recayendo la furia de Zeus. 


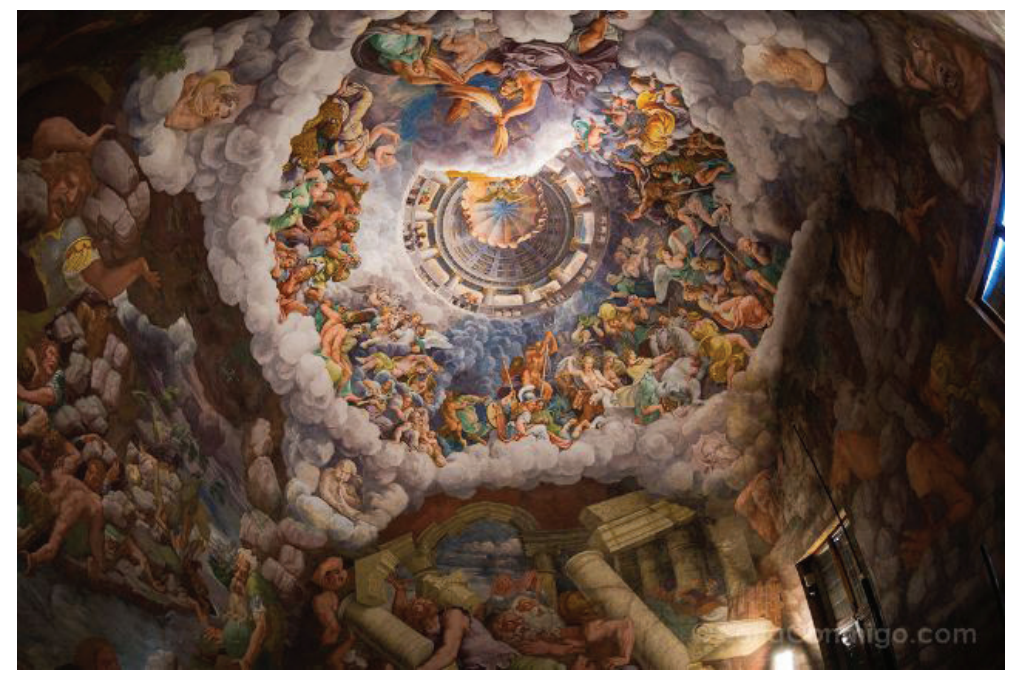

Imagen 5: La caída de los Gigantes en el Palacio del Té.

Giulio Romano (1532-1535). Palacio del Té (Mantua)

Según Paoletti y Radke, los frescos de la Sala de los Gigantes, encargados a Romano por Federico II Gonzaga (duque de Mantua), se deben a la segunda visita que realizó el emperador Carlos V a Mantua (2002: 417-418). Se establece, por consiguiente, un vínculo directo entre el poder del emperador y el de Zeus, redundando en el sentido completamente propagandístico de la obra.

Más adelante, durante el Barroco, la suntuosidad de la corte de Luis XIV dejó en los jardines de Versalles una original representación de la Gigantomaquia: la fuente de Encélado (imagen 6). Realizada por Gaspard Marsy, aquí el gigante Encélado es engullido por la lava volcánica, siguiendo el relato de Apolodoro: "Atenea arrojó sobre Encélado fugitivo la isla de Sicilia y habiendo arrancado la piel a Palante, con ella protegió su propio cuerpo en el combate" (1985: 53). El gigante trata de escapar de su doloroso final, retorciéndose mientras grita. Al estar integrado en una fuente, el agua que expulsa forma parte del dinamismo de la narración, destacando el chorro que sale de su boca en forma de grito. "Resulta magistral", comenta Rodríguez López sobre la obra, "el contraste barroco en- 
tre las texturas de la lava y la dorada figura del gigante, que simula un auténtico 'tableu vivant"' (2009: 22). Según la autora, la caída del gigante debe leerse en clave política: Encélado es el enemigo de Luis XIV, que cae vencido ante el poder del monarca (RODRÍGUEZ LÓPEZ, 2009: 22).

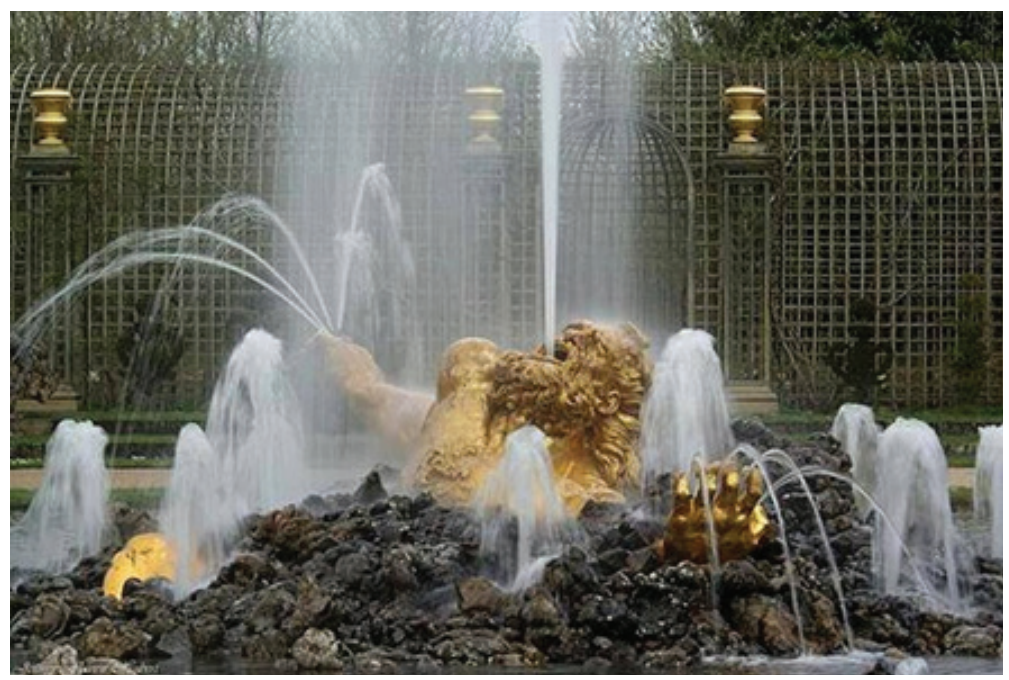

Imagen 6: Fuente de Encélado en Versalles. Gaspard Marsy (1675-1677). Palacio de Versalles

En los primeros pasos del Neoclasicismo se encuentra el boceto que realiza el español Francisco Bayeu para la decoración del techo de la pieza de besamanos en el cuarto de los Príncipes de Asturias del Palacio Real de Madrid ${ }^{5}$ (imagen 7). En la imagen se observa a Zeus, iluminado (e iluminando al resto de dioses) y ocupando el centro de la escena. Con su mano derecha lanza sus rayos hacia abajo, en el epicentro de un revuelo de dioses en espiral que remite directamente al dinamismo de la anterior obra de Romano (imagen 5). Gracias sus atributos, se pueden identificar el

5 https://www.museodelprado.es/coleccion/obra-de-arte/el-olimpo-batalla-de-los-gigantes/b12804d1-a48e-4288-927c-38f3cd19c05b (22-6-2020). 
resto de dioses, entre los que destacan Atenea, Hermes o Dioniso. En su Descripción de las alegorías pintadas en las bóvedas del Real Palacio de Madrid, Francisco José Fabre explica que esta pintura mural es “emblema de los atentados de rebelión" (1829: 28), por lo que debe interpretarse dentro de la idea bajo la que se había diseñado el resto de frescos del palacio: demostrar la gloria de la monarquía española (Díaz Gallegos, 2001). De nuevo, la Gigantomaquia encaja a la perfección entre los programas iconográficos que pretenden legitimar el poder a través del arte.

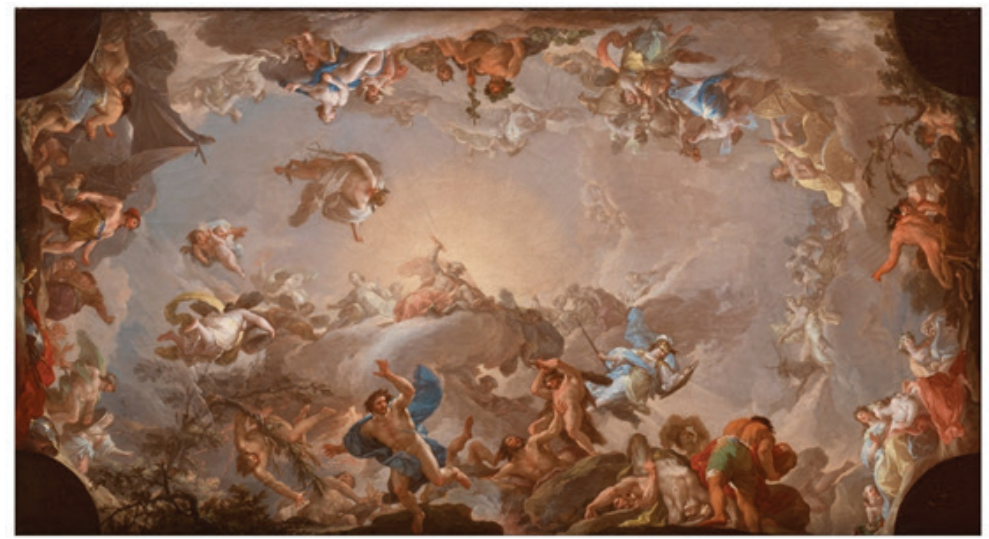

Imagen 7: El Olimpo. Batalla de los Gigantes. Francisco Bayeu (1767-1768). Museo del Prado (Madrid)

Con la irrupción de la Revolución Francesa, comienza a establecerse un nuevo orden social a partir del siglo XIX en el que obras de propaganda artística como las que hasta aquí se han comentado dejan de ser tan frecuentes: los nuevos gobiernos ya no ostentan el poder absoluto de las antiguas instituciones, como la monarquía o la Iglesia. Por ello, cesan los encargos directos de obras propagandísticas de gran magnitud, mientras que, al mismo tiempo y para lograr vivir de la profesión, los artistas se abren a un mercado creciente dirigido por premisas más económicas que políticas. Este es el contexto en el que se ha ido fraguando el arte de los siglos XIX y XX, donde aún se representan escenas mitológicas, aunque con fines distintos a 
los de legitimar el poder político imperante. Es el caso, por ejemplo, de la serie de Gigantomachy de Leon Golub (imagen 8), perteneciente ya a la segunda mitad del siglo XX. En la serie, como se aprecia en esta segunda pieza, no puede determinarse quiénes son los Gigantes y quiénes los dioses, pues en esta contienda todos están despojados de sus atributos y, además, de sus pieles. Así pues, no puede existir una legitimación del poder de los vencedores frente a los vencidos. Todos son figuras que muestran el interior de sus cuerpos, formados por venas y arterias, pero en los que aún se adivina la expresión de furia y horror de cada personaje. Con la distribución espacial de las figuras característica de los frisos clásicos, Golub reproduce una desgarradora lucha con la que, por iniciativa propia, critica la injusticia, la violencia y la crueldad del ser humano ${ }^{6}$.

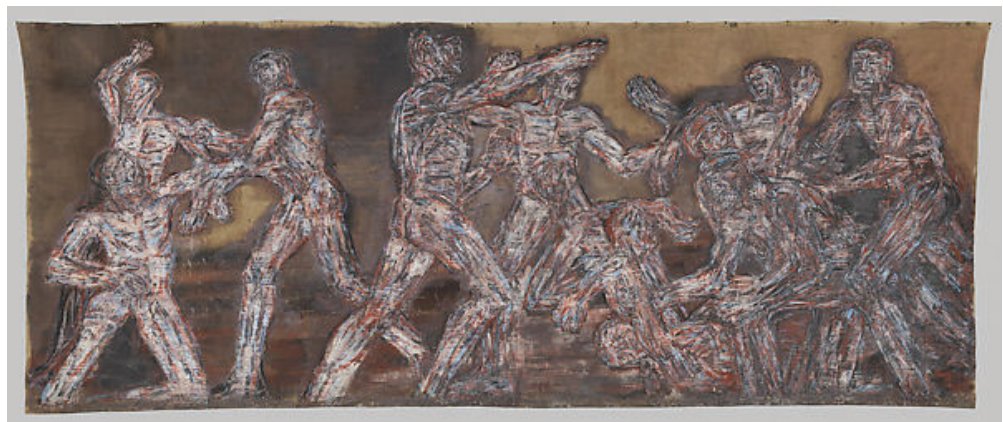

Imagen 8: Gigantomachy II. Leon Golub (1966).

Metropolitan Museum (Nueva York)

\section{Conclusiones}

La Gigantomaquia es un mito cosmogónico en el que se decide el orden que va a imperar en el mundo: con esta contienda, los dioses del Olimpo, ayudados por el mortal Heracles, demuestran su superioridad y su astucia frente al ataque de los Gigantes, unos seres que se habían criado para ser invencibles. El mito culmina con una acusada división entre valores dicotómicos como orden/desorden o gloria/condenación. La terrible caracterización del enemigo, por

6 https://www.metmuseum.org/art/collection/search/725889 (22-6-2020). 
un lado, y la gloria de los que se alzan con la victoria, por otro, son tan tajantes que el episodio mitológico, como se ha observado en el anterior recorrido histórico, ha cumplido las mismas funciones propagandísticas en distintas épocas. Esto demuestra su eficacia comunicativa a lo largo de la historia, dirigiéndose a un espectador cuya mirada ya estaba educada desde la época clásica para una única interpretación de esta representación iconográfica.

En definitiva, la Gigantomaquia es un mito eminentemente político que ha tenido una intensa explotación a la hora de asociar la supremacía del poder que encargaba la obra con las indestructibles divinidades del Olimpo.

\section{Referencias}

APOLODORO. Biblioteca mitológica. Introducción de Javier Arce. Traducción y notas de Margarita Rodríguez de Sepúlveda. Madrid: Gredos. 1985.

DELGADO LINACERO, Cristina. La Gigantomaquia, símbolo socio-político en la concepción de la polis griega". En: Espacio, Tiempo y Forma, Serie II, Historia Antigua, 12, pp. 107-127. 1999.

DELGADO LINACERO, Cristina. El grandioso altar de Pérgamo: Emblemática obra del mundo helenístico. En: Cuadernos de Filología Clásica: Estudios griegos e indoeuropeos, 12, pp. 329-344. 2002.

DÍAZ GALLEGOS, Carmen. Las decoraciones murales en la planta principal del Palacio Real de Madrid. En: Arbor, CLXIX [665], pp. 59-81. 2001.

ELVIRA BARBA, Miguel Ángel. Arte y Mito. Manual de iconografía clásica. Madrid: Sílex. 2008.

FABRE, Francisco José. Descripción de las alegorías pintadas en las bóvedas del Real Palacio de Madrid. Madrid: Eusebio Aguado, Impresor de Cámara de S.M. 1829.

HESÍODO. Teogonía. Introducción, traducción y notas de Aurelio Pérez Jiménez y Alfonso Martínez Díez. Madrid: Gredos. 1978.

OVIDIO Metamorfosis. Traducción de Ana Pérez Vega. 1983. Disponible en: https://www.academia.edu/35761762/Ovidio_Metamorfosis_bilingue (20-6-2020). 
PAOLETTI, John T. y.; RADKE, Grary M. El arte en la Italia del Renacimiento. Madrid: Akal. 2002.

PÍNDARO. Odas y fragmentos. Olímpicas. Píticas. Nemeas. Ístmicas. Fragmentos. Introducciones, traducción y notas de Alfonso Ortega. Madrid: Gredos. 1984.

RODRÍGUEZ LÓPEZ, María Isabel. El asalto al Olimpo: La Gigantomaquia. En: De Arte, 9, pp. 7-26. 2009.

WATROUS, Livingston Vance. The Sculptural Program of the Siphnian Treasury at Delphi. En: American Journal of Archaeology, 86[2], pp. 159-172. 1982.

WHITAKER, Richard. Art and Ideology: The Case of the Pergamon Gigantomachy. En: Acta Claassica, 48, pp. 163-174. 2005.

WILSON, R. J. A. (2012): "Piazza Armerina". En: Bagnall, R.S./Brodersen, K./ Champion, C.B./ Erskine, S.R./Huebner, A. (eds.): The Encyclopedia of Ancient History. 2012. 